\title{
Knowledge of Alzheimer's Disease Among Medical Students of a Medical College
}

\author{
Rachana Sharma, ${ }^{1}$ Subhash Chandra Sharma, ${ }^{1}$ Sudarshan N Pradhan, ${ }^{1}$ Pratikshya Chalise, ${ }^{1}$ Luna Paudel \\ 'Department of Psychiatry, Kathmandu Medical College, Sinamangal, Kathmandu, Nepal.
}

\section{ABSTRACT}

Introduction: Dementia is a public health concern as the prevalence is increasing worldwide with significant increase being in low-middle income countries. However these countries appear to be less prepared in handling this rise in terms of diagnosis and management.

Methods: This cross-sectional study was conducted in Kathmandu medical College, from June 2017 to July 2017. Purposive sampling was done and the medical students who were in their first and final year of study were included in the study after obtaining an informed consent.

Results: Total 185 students were included in the study, 80 (43.24\%) from first year and 105 (56.75\%) from final year of medical study. The mean score of knowledge among the students was $17.44 \pm 2.46$; $15.32 \pm 1.22$ among first year and $19.06 \pm 1.87$ among the final year students. Majority of the students said they have heard about dementia however, only 3 (3.75\%) of first year and 43 (41.9\%) from final year students have either attended a class or continuing medical education on dementia

Conclusions: The knowledge about dementia was found to be average among medical students but better among final year medical students in comparison to first year. The knowledge was found to be better statistically among those who had either attended a class or continuing medical education on dementia or had exposure through different medias.

Keywords: alzheimer's disease; dementia; knowledge; medical students.

\section{INTRODUCTION}

Dementia is a growing public health problem and the prevalence of dementia is rising globally with significant increase being in low-middle income countries. ${ }^{1}$ Epidemiological survey on dementia hasn't been done in Nepal. However, two thesis done by psychiatry resident in a tertiary level hospital of eastern Nepal, found the prevalence of dementia to be around $12 \%$ in population above 60 years. ${ }^{2-3}$ However the health care system of these countries are less prepared to handle these rise in numbers of patients with dementia in terms of diagnosis and management. ${ }^{4}$

In context of Nepal, there is lack of specialized care specialist thus major responsibility for diagnosis and management lies on the medical graduates. However medical schools in Nepal provide minimal training in geriatric medicine and dementia care in undergraduate level, ${ }^{5}$ and thus the knowledge of medical students regarding dementia can be presumed to be limited.

The study was designed to assess the knowledge of first and final year medical students regarding Alzheimer`s Disease.

Correspondence: Dr. Rachana Sharma, Department of Psychiatry, Kathmandu Medical College, Sinamangal, Kathmandu, Nepal. Email: srachana@hotmail.com, Phone: +977-9851102679. 


\section{METHODS}

This cross-sectional study was carried out among the first and final year medical students of Kathmandu Medical College from June 2017 to July 2017. Approval for the study was obtained from Ethical committee and Institutional Review Committee of Kathmandu Medical College. The students were approached in person in their class and explained briefly about the study. The consenting students meeting our research criteria were enrolled in the study. The inclusion criteria of the study were: i) Those students who are either in first year or final year of medical school ii) Those students who agree to participate in the study.

Self-designed, semi-structured proforma was used to collect the background information like sociodemographic profile of the students and some information regarding dementia. Alzheimer's Disease knowledge Scale (ADKS) was used to assess the students' knowledge on different aspects of Dementia. ADKS was used because of its ease to use, demonstrated reliability and validity and applicability for different groups of participants (health professionals, general public and caregivers). The ADKS consists of 30 true/ false items with the resulting score being the numbers answered correctly. Reliability of the ADKS measured by test-retest correlation is 0.81 ; internal consistency, as measured by the average inter-item correlation of $\square$ is 0.71 and content/ predictive validity is adequate. The data was analyzed using SPSS version $20{ }^{6}$

\section{RESULTS}

In this study, total of 185 students both from first and final year participated. The students were from 18 years to 26 years of age and the mean age was $21.16 \pm 4.86$ years. Seventeen individuals $(9.2 \%)$ said they had some family members or friends suffering from dementia, among them, $6.5 \%$ said their close relatives were suffering from dementia (Grandmother and Grandfather), $0.5 \%$ said their distant relative had dementia and the remaining didn't specify. Other relevant socio-demographic details of the participants are given (Table 1 ).

Students were asked to self-rate their knowledge on dementia on a scale of 0-10. Among 185 students, 174 $(94.05 \%)$ rated their knowledge whereas 11 students $(5.95 \%)$ didn't mention anything. The total mean score among 174 students was $3.60 \pm 1.87$, minimum being 0 and maximum being 10 . The mean score among first year students was $2.99 \pm 1.74$, whereas it was $4.04 \pm 1.85$ among final year students. The difference between self-rated knowledge was found to be statistically significant. Students knowledge was further assessed using Alzheimer`s Disease Knowledge Scale (ADKS). The mean score among 185 students was $17.44 \pm 2.46$; the mean score among first year students was $15.32 \pm 1.22$ whereas that among final year students was $19.06 \pm 1.87$. The difference between first and final year score was found to be statistically significant. The difference in knowledge among first and final year students (both self-rated and according to ADKS) was also found to be statistically significant according to Spearman `s correlation. Other relevant difference among first and final year students are given (Table 2).

\begin{tabular}{|lll|}
\hline \multicolumn{3}{|l|}{ Table 1. Sociodemographic profile of participants. } \\
\hline Variable & Male & $115(62.2)$ \\
Gender & Female & $70(37.8)$ \\
Year of Medical School & First & $80(43.2)$ \\
& Final & $105(56.8)$ \\
Ever heard about Dementia & Yes & $176(95.1)$ \\
& No & $9(4.9)$ \\
Ever attended classes or & Yes & $47(25.4)$ \\
CME on Dementia & No & $138(74.6)$ \\
Ever been educated about & Yes & $86(46.5)$ \\
Dementia & No & $99(53.5)$ \\
Family or friends suffering & Yes & $17(9.2)$ \\
from Dementia & No & $168(90.8)$ \\
Ever studied about & Yes & $70(37.8)$ \\
Dementia on your own & No & $115(62.2)$ \\
\hline
\end{tabular}

Among the 80 first year and 105 final year medical students, $74(92.5 \%)$ and $102(97.14 \%)$ respectively said that they have heard about dementia through various sources. However, the difference was not found to be statistically significant. Similarly $3(3.75 \%)$ of 80 first year students and $43(41.9 \%)$ of 105 final year students said that they have either attended a class or CME on dementia and the difference was found to be statistically significant. Most of the students 115 $(62.2 \%$ including both first and final year) said that they haven't studied about dementia on their own and the difference between first and final year students was not statistically significant. However, when asked whether they have been educated about dementia via any means, 63 (60\%) final year students and $23(28.75 \%)$ first year students responded "Yes" and the difference was statistically significant. The two factors that were found to be significantly associated with better knowledge about dementia among medical students were attending class or CME and being educated about 
dementia via different media $(P=0.000)$.

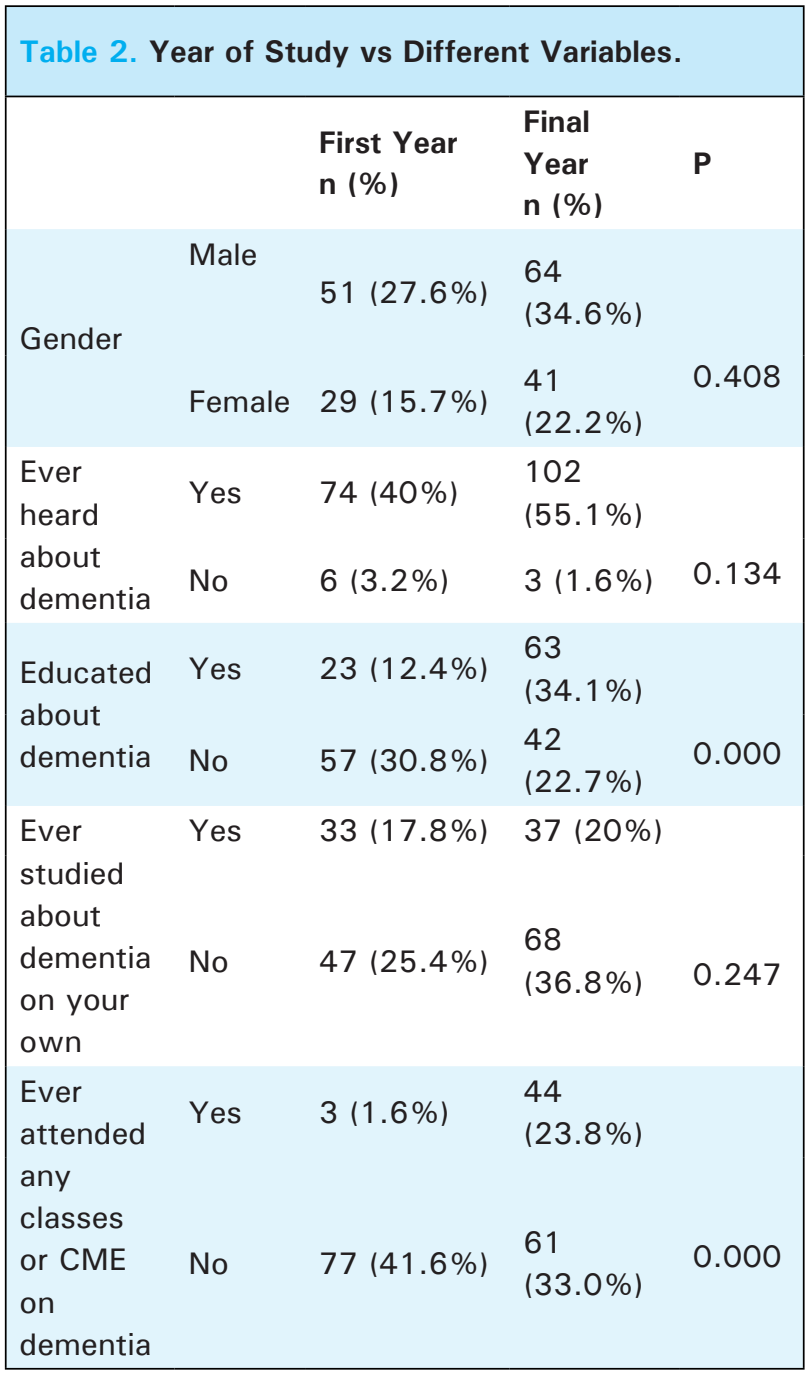

\section{DISCUSSION}

This study was conducted with the primary objective of evaluating the knowledge of medical students (first and final year) regarding dementia. In the study it was found that final year medical students had better knowledge both self-rated and according to ADKS than first year, meaning that those who self-rated their knowledge to be good scored well on ADKS as well. Similar finding was noted in a study conducted among medical students in $\mathrm{US}^{7}$ as well as in a study conducted in Queensland, Australia among different health care staffs. ${ }^{8}$

Out of 30 questions first year students on average answered $50 \%$ questions correctly whereas final years score was $63 \%$ on average. In an average, the correct response was just above $50 \%$ among first and final year students, which can be said to be limited if not poor. The knowledge was found to be better (statistically significant) among those who had either been educated about dementia via different means like newspaper, television, radio etc and among those who have attended either class or CME on dementia. In a study conducted among different health care staffs in Australia, found the average percentage of correct response among participants to be $79 \%{ }^{8}$ which was higher than our study. One possible reason to this might be Australia being developed nation has better access to various media compared to ours. The other possible reason might be the sample population. Australian study included medical professionals who were directly involved in treating and caring the patient whereas our study only included medical students who had no or limited contact with patients with dementia.

In a similar study conducted among final and first year medical students of various medical schools of United States showed similar results like ours in which final year students scored relatively better than first year and those students whose family member or friends had AD were more likely to perform well. ${ }^{7}$ However, in our study having a family member or friend with dementia didn't affect the knowledge of the students. The possible reason for this might be because our students mightn't have been directly involved in taking care of the family member suffering from dementia.

Our study revealed positive correlation between knowledge about dementia and self- rated dementia knowledge and having attended dementia related class or media exposure. Our finding is in accordance to the study conducted in Australia among health care staff (clinical and non-clinical) which showed those who have attended dementia related class had better knowledge. ${ }^{8}$ In another similar study conducted in Hong Kong also revealed that attending more hours of class was related to the better level of knowledge of dementia. ${ }^{9}$ Similarly another study conducted in the United State among various groups also concluded that attending dementia related classes and exposure to multiple information sources enhanced the knowledge regarding dementia. ${ }^{10}$ Both, attending more hours and getting exposed to various media regarding dementia is a positive attribute to improving knowledge.

One of the major limitations of this study was that it assessed the knowledge of medical students of a single medical college. We have various medical colleges under different universities in our country which have their own curriculum. A multi-centric study among students of various medical colleges would give a better picture of the scenario. Nevertheless, through this study finding I would like to emphasize on the need to improve the knowledge of medical students regarding dementia as in a developing country like ours WHO has estimated the burden of disease to be high and medical graduates are the primary contact for patients initially. So, preparation 
of medical graduates is of utmost importance.

\section{CONCLUSIONS}

According to this study, final year medical students were found to have better knowledge regarding dementia than first year students though the overall

\section{REFERENCES}

1. Alzheimer`s disease International. World Alzheimer`s Report 2015 [Internet]. Alzhiemer Disease International;2015 [Cited 2018 Feb 12]. [Full Text]

2. Paudel L. Prevalence of depression among geriatric patients attending tertiary hospital. [Nepal]. BP Koirala Institute of Health Sciences. 2015. 103p. English. [Full Text]

3. NepalS. Prevalence of dementia in old age patients attending psychiatric clinic in a tertiary care center over a period of one year [Nepal]. BP Koirala Institute of Health Sciences. 2014. 85 p. English. [Full Text]

4. Prince M, Bryce R, Albanese E, Wimo A, Ribeiro W, Ferri CP. The global prevalence of dementia: A systematic review and metaanalysis. Alzheimer`s and Dementia. 2013;9(1):63-75. [PubMed | DOI]

5. Gautam PC. Introducing geriatric medicine to Nepal: an outline of a training program and a model for the delivery of services. Kathmandu University Medical Journal. 2008; 6(21):135-40. [Full Text] knowledge was found to be just above average. The knowledge was found to be better among those who had attended either CME or any classes on dementia and among those who had media exposure regarding the same.

Conflict of Interest: None.

6. Carpenter BD, Balsis S, Otilingam PG, Hanson PK, Gate M. The Alzheimer`s disease knowledge scale: Development and psychometric properties. Gerontologist. 2009;49(2):236-47. [PubMed | DOI]

7. Nagle BJ, Usita PM, Edland SD. United States medical student`s Knowledge of Alzheimer`s diseas. J Educ Health Prof. 2013;10:4. [ubMed | DOI]

8. Smyth W, Fielding E, Beattie E, Gardner A, Moyle W, Franklin $S$ et al.A survey based study of knowledge of Alzheimer's disease among health care staff. BMC Geriatrics. 2013;13:2. [PubMed | DOI]

9. Kwok T, Lam K, Ho F. Knowledge of Dementia among Undergraduates in health and social care professions in Hong kong. Social work in Mental Health. 2011;9:287-301. [Full Text]

10. Carpenter BD, Zoller SM, Balsis S, Otilingam PG, Gatz M. Demographic and Contextual Factors Related to Knowledge About Alzheimer`s Disease. Am J Alzheimers Dis Other Demen. 2011 March;26(2):121-6. [PubMed | PMC]

\section{The Author(s) 2018.}

This work is licensed under a Creative Commons Attribution 4.0 International License. The images or other third party material in this article are included in the article's Creative Commons license, unless indicated otherwise in the credit line; if the material is not included under the Creative Commons license, users will need to obtain permission from the license holder to reproduce the material. To view a copy of this license, visit http://creativecommons.org/licenses/by/4.0/ 